\title{
A EXTENSÃO POPULAR E BIOCÊNTRICA: VIVÊNCIAS EM FORMAÇÃO universitária no Ceará e Rio Grande do Sul
}

\section{Popular and Biocentric Extension experiences: university training people in Ceará and Rio Grande do Sul La extensión popular y biocentrica: vivencias en formación
universitaria en Ceará y Rio Grande do Sul}

\author{
Ana Luisa Teixeira de Menezes ${ }^{1}$
}

Verônica Morais Ximenes ${ }^{2}$

\begin{abstract}
RESUMO
Este artigo é uma síntese de trabalhos e pesquisas que vêm sendo desenvolvidos no Núcleo de Psicologia Comunitária da Universidade Federal do Ceará e na Universidade de Santa Cruz do Sul. São referências que combinam em suas metodologias a busca da autonomia através da mobilização comunitária e a educação popular e biocêntrica, que traz a discussão da Vida como centro do Universo. Desenvolvemos a relação entre extensão e sabedoria, a partir de estudos em Psicologia Comunitária com os povos ameríndios, especificamente os Guarani, problematizando o sentido de conhecimento e da própria extensão em sua relação com a pesquisa e o ensino na formação universitária. Para os povos Guarani a aprendizagem é desenvolvida como desejo de saber e inclui a corporeidade, a intuição, a espiritualidade e o pensamento dentro de um propósito coletivo de organização. Esta concepção sobre o conhecer é parte de nossa cultura, sendo muitas vezes deixada de lado por não representar o conhecimento europeu e econômico dominante, mas se encontra com as nossas práticas de formação universitária. A extensão possibilita uma formação integral e transdisciplinar, sendo necessária como formação humana e profissional.

Palavras-chave: extensão popular; educação biocêntrica; psicologia comunitária; universidade; saberes ameríndios.
\end{abstract}

\begin{abstract}
This article is a summary of works and research being developed in Núcleo de Psicologia Comunitária - NUCOM (Community Psychology project - NUCOM) of the Federal University of Ceara and the University of Santa Cruz do Sul. It provides references that combine their methodologies. It discusses the quest for autonomy through community mobilization and biocentric education and that brings the debate of life as the center of the universe. It develops the relationship between extension and wisdom from studies in Communitarian Psychology and about the Amerindian people, specifically the Guarani, problematizing the meaning of knowledge itself and its relation with extension, research and teaching in university studies. For the Guarani people learning is developed as a desire to know, which includes corporality, intuition, spirituality and thinking in a collective organization purpose. Their view about knowledge is part of our culture and it is often left out because it does not represent the dominant economic and European knowledge, but it with our practice of university education. The extension provides a full and transdisciplinary training, and is necessary as a human and professional education.

Keywords: Popular extension; Biocentric Education; Community Psychology; University; Amerindian people knwoledge.

\footnotetext{
1 Graduada em Psicologia na Universidade Federal do Ceará, Mestre em Psicologia Social e da Personalidade pela PUC/RS, Doutora em Educação pelo Programa de Pós Graduação em Educação da UFRGS, Professora de Psicologia do Departamento de Psicologia da UNISC e Pró-Reitora de Extensão e Relações Comunitárias da UNISC. Endereço: Universidade de Santa Cruz do Sul - Av. Independência, 2293. CEP: 95815-900 - Santa Cruz do Sul - RS. E-mail: luisa@unisc.br, luisabio@hotmail.com. Fone: (051) 97142969.

2 Graduada em Psicologia na Universidade Federal do Ceará, Doutora em Psicologia pela Universidade de Barcelona, Professora da Graduação e do Mestrado em Psicologia da UFC, Coordenadora do Núcleo de Psicologia Comunitária (NUCOM) e Coordenadora do Mestrado em Psicologia. Email: vemorais@yahoo.com.br. Fone: (085) 33667729.
} 


\section{RESUMEN}

Este artículo es un resumen de los trabajos e investigaciones que se están desarrollando en el Núcleo de Psicología Comunitaria, Universidad Federal de Ceará y de la Universidad de Santa Cruz do Sul. Son referencias que se combinan en sus metodologías en la búsqueda de la autonomía a través de la movilización de la comunidad y la educación popular y biocêntrica, que lleva la discusión de la vida como centro del universo. Estamos desarrollando la relación entre la extensión y la sabiduría de los estudios en Psicología Comunitaria y con los pueblos amerindios, especialmente los Guaraní, problematizando el sentido del conocimiento en sí mismo y su ampliación en relación con la investigación y la enseñanza en la educación universitaria. Para los pueblos Guaraní, el aprendizaje se desarrolla como un deseo de saber, e incluye el cuerpo, la intuición, la espiritualidad y el pensamiento dentro de objectivo de organización colectiva. Este concepto se conoce por parte de nuestra cultura y con frecuencia no representan a cabo por la economía dominante y europea del conocimiento, pero se encuentra con nuestra práctica de la enseñanza universitaria. La extensión permite una formación plena y transdisciplinar, siendo necesaria a formación humana y profesional.

Palabras-clave: Extensión popular; Educación Biocêntrica; Psicología Comunitaria. Universidad; conocimientos de los amerindios.

\section{Introdução}

Nossa experiência em extensão e, mais especificamente, no Núcleo de Psicologia Comunitária da UFC, durante a graduação em Psicologia, possibilitou-nos fazer uma articulação entre ensino, pesquisa e extensão na relação com a produção do conhecimento. Mesmo sabendo que os trabalhos de extensão nas universidades, muitas vezes, ainda não ocupam espaços significativos nas instâncias de ensino, gostaríamos de destacar algumas experiências e reflexões, dentre tantas outras que merecem ser evidenciadas, no sentido de provocar e nos fazer pensar sobre os avanços e a revitalização da extensão nas universidades.

A história da extensão caminha lado a lado com uma história de resistência e de reconstrução de formas de vida, de cultura $e$ de saber. Melo Neto (2006) define a extensão popular como uma forma de trabalho útil para a sociedade e nos alerta sobre os perigos deste tipo de trabalho se tornar alienante. Nesse sentido, afirma que a extensão deve ser mais do que troca de saberes científicos e populares e, sim, que esta deve exercer uma força na produção de um conhecimento que busca transformar as condições de opressão vivida por grande parte de nossa população. Tarefa esta que requer muita concentração, atenção, reflexão, sistematização e problematização. Sabemos que a extensão não pode caminhar sozinha, mas consideramos fundamental evidenciar o seu papel frente ao ensino e a pesquisa e a sociedade.

Góis (2008), pautado no princípio biocêntrico, que será desenvolvido ao longo desse artigo, indaga sobre o sentido das transformações culturais: o que tem orientado nossas mudanças culturais? Onde nos referenciar? Tais perguntas são norteadoras de nossas práticas de extensão no Ceará e no Rio Grande do Sul, que visam fundamentalmente desenvolver uma sabedoria pautada na Vida, sendo esta o sentido de nossas investigações e ações.

\section{Diálogos com a Extensão}

Paulo Freire (1977) propôs pensarmos a extensão como uma prática de comunicação, na qual o diálogo existe dentro de uma construção do conhecimento. Isso nos parece de uma simplicidade e de um desafio. Acreditamos, a partir de Freire (1977), que desenvolver a comunicação com o mundo vivido e sua complexidade é um dos grandes desafios das universidades, tanto públicas como particulares e comunitárias. A Extensão possibilita, através da Universidade, o discernimento sobre as diversas realidades. 
Como percebê-las numa interação investigativa e problematizadora?

Ao problematizar realidades, estamos também, enquanto professores e cidadãos, questionando a nossa ação e o nosso pensamento $e$, assim, exercitando a nossa condição intrínseca de ser humano, de criação, a capacidade de ser na ação, no movimento.

O termo extensão universitária possui diferentes interpretações dependendo do lugar em que esta é vivenciada. Na Universidade, a extensão está presente como um dos elementos do tripé do ensino superior, formado pelo ensino, pesquisa e extensão, porém na prática não possui sua devida importância na formação acadêmica de alunos e professores. $\mathrm{O}$ ensino e a pesquisa possuem um lugar de destaque na Universidade. Segundo Nogueira (2005), a extensão deve ser repensada enquanto atividade acadêmica que possibilita a democratização do conhecimento, o atendimento às demandas da população $e$ o confronto do conhecimento com situações concretas:

O Projeto Político Pedagógico da Universidade pode ser um instrumento que possibilite o diálogo entre ensino-pesquisa-extensão, pois poderá definir as políticas institucionais que permearão a vida da instituição. Mais especificamente, os Projetos Político Pedagógico dos Cursos de Graduação também são importantes instrumentos na incorporação da extensão e da pesquisa como elementos curriculares (XIMENES; NEPOMUCENO; MOREIRA, 2007, p. 22).

Para a comunidade, formada por pessoas ricas e pobres que não estão trabalhando ou estudando na universidade, a extensão é vista de várias formas: prestação de contas do dinheiro público, caridade em realizar serviços para pessoas pobres, caminho para os acadêmicos testarem suas teorias, lugar que possibilita o diálogo entre o conhecimento popular e o científico, contato com a realidade local.
Existem tipos diferentes de extensão? Extensão é prestação de serviços à comunidade? É responsabilidade social? É elemento importante na formação acadêmica de alunos e professores? É um possível caminho de libertação do povo oprimido? É lugar de desenvolvimento de teorias e de pesquisas?

A partir de nossas experiências em extensão universitária como alunas da graduação em Psicologia e atualmente como professoras universitárias, vivenciamos as facilidades $e$ as dificuldades de desenvolver atividades no ambiente contagiante que a extensão propicia, quando acreditamos que ela é um caminho de transformação pessoal e profissional de alunos, professores e técnicos, como também dos moradores das comunidades.

A prática extensionista não é neutra. Acreditamos e praticamos uma extensão comunitária/libertadora comprometida com a transformação social da classe pobre e oprimida. Encontramos vários teóricos que discutem o conceito de extensão dentro de uma perspectiva de engajamento e compromisso social. Podemos citar alguns: Tavares (2001), Sousa (2001), Batomé (2001), Faria (2001), Rocha (2003), Branco e Guimarães (2003), Thiollent (2003), Ximenes e Góis (2004), Falcão (2006), Jenize (2006) e Frantz e Silva (2002).

Ximenes, Nepomuceno e Moreira (2008), em uma pesquisa em que ouviram 35 pessoas, entre professores, estudantes, profissionais e moradores de três comunidades cearenses, sobre a prática extensionista da Psicologia Comunitária desenvolvida pelo Núcleo de Psicologia Comunitária (NUCOM), relatam:

No NUCOM, a partir do seu princípio teoria-prática-compromisso social, compreende-se que a atuação extensionista tem um engajamento profundo com as questões concretas da realidade e que ela se baseia em um propósito de transformação desta realidade, onde existe 
uma intencionalidade e um propósito a ser alcançado. $\mathrm{O}$ que se alinha com o propósito da própria Psicologia Comunitária, de buscar trazer a Psicologia para as reais questões da sociedade brasileira e nordestina, através de uma atuação que compreende que desenvolvimento pessoal e transformação social estão intimamente imbicados (XIMENES;NEPOMUCENO; MOREIRA, 2008, p. 83).

Compreendemos e praticamos o conceito de extensão que valoriza a cooperação entre todos os atores envolvidos no processo, gerando um novo conhecimento que nasce da simbiose do conhecimento científico com o conhecimento popular:

Esta prática implica, por isto mesmo, que o acercamento as massas populares se faça, não para levar-lhes uma mensagem "salvadora", em forma de conteúdo a ser depositado, mas para, em diálogo com elas, conhecer, não só a objetividade em que estão, mas a consciência que tenham desta objetividade; os vários níveis de percepção de si mesmos em que e com que estão. Por isso é que não podemos, a não ser ingenuamente, esperar resultados positivos de um programa, seja educativo num sentido mais técnico ou de ação política, se, desrespeitando a particular visão do mundo que tenha ou esteja tendo o povo, se constitui numa espécie de "invasão cultural", ainda que feita com a melhor das intenções. Mas invasão cultural sempre (FREIRE, 1987, p. 86).

Um dos grandes papéis da extensão é provocar nossas comunidades e nossas regiões a pensarem sobre suas ações, tornando a aprendizagem um ato de transformação. $\mathrm{O}$ trabalho de extensão convida aos professores, aos alunos, aos gestores e técnicos a serem aprendizes. Ao falarmos de extensão e conhecimento trazemos a concepção ameríndia de educação como uma forma de diálogo com os nossos modelos de aprendizagem. Góis (2008) nos faz lembrar do sentido da Ameríndia enquanto uma América que inclui os povos pré-colombianos e outros povos diversos que remontam dos primeiros habitantes pré-históricos até os nossos dias. Bergamaschi (2005) revela que um dos princípios da educação Guarani é o estímulo à curiosidade, ao desejo de aprender. Menezes (2006), em seus estudos sobre a dança Guarani, relata a gestualidade das crianças e relaciona a liberdade de movimentos vivida por elas à curiosidade, ao desejo de saber. Aprendizagem esta, que está diretamente ligada às sensações, à espiritualidade e à corporeidade e que também nos permite descobrir novos cheiros, odores, sons, ambientes que, se por um lado podem gerar desconfortos, ao mesmo tempo geram um profundo sentimento de estar vivo como o que a autora abaixo destaca:

\begin{abstract}
Sinto-me instigada a seguir, também, um conhecimento apreensível com o coração, e escrever desde o ponto de vista da vida, elaborando contornos móveis, onde caiba o movimento e a processualidade daquilo que não é capturável (BERGAMASCHI, 2005, p. 56).
\end{abstract}

A processualidade do que não é capturável está ligada aos aspectos sensíveis, intuitivos, afetivos e simbólicos da experiência vivida. Unger (2001) salienta que a força simbólica possibilita um encontro com as forças criadoras de origem, deixando emergir o nascimento do novo, ou seja, fazer renascer continuamente "uma postura existencial que se ponha à escuta da vida e de seus sinais". Este tipo de saber, segundo a autora, é organizado pelo ritmo e pela experiência e, é gerador de uma ética vitalizadora de sua morada. É uma ética que nasce da vida, da compreensão desses saberes como algo internalizado na organicidade do ser. 
É um saber que estimula a escuta dos sentidos, da intuição, que se abre permanentemente na busca do decifrar e, assim, atualiza e renova as capacidades para o conhecimento.

O conhecimento, nesta perspectiva, também é algo mutável, não é estagnado, é flexível. Quando um conhecimento se torna rígido ele perde a capacidade de se transformar $e$, assim, torna-se o que podemos observar nos dogmas, que são crenças ou conteúdos que não admitem contestação, provocando intolerância e sofrimento nos sujeitos ou sociedades envolvidas.

Ao contrário, existe um tipo de conhecimento que os Guarani ${ }^{3}$ denominam sabedoria, saber e discernimento, que vai sendo experienciado ao longo do tempo e que necessita da vivência. Segundo "seu" Adolfo, um velho Guarani, a aprendizagem vem da vivência e faz "sentido no coração, no pensamento, lá no centro no céu" (MENEZES, 2006).

Esta forma de conhecer revela a noção do tempo. O Guarani vive a aprendizagem como sabedoria de vida. Marcos, jovem Guarani, ao falar da dança, refere-se a esta como um conhecimento do Arandu que envolve o conhecer pela vivência, pelo tempo da experiência e relata que "Ara é o que faz todos os dias e ndu é o tempo de aprendizagem" (MENEZES, 2006, p.10).

A noção de conhecimento Guarani, além de revelar o sensível, dá-se dentro de uma ótica de enraizamento comunitário. Menezes (2006) revela que quando estava pesquisando sobre a dança entre os Guarani, num primeiro momento frustrou-se, alegando que não existia um eu pessoal, depois entendeu que não existe um "eu" sem um "nós", e que entender as falas pessoais sem compreender o todo, ou seja, a cosmologia Guarani, tornar-se-ia uma missão impossível de realizar.

Um dos grandes desafios e impasses vividos na extensão é discutir e compreender sobre esta relação entre pessoal e coletivo. Dentro de uma sociedade profundamente individualizada, como trabalhar com o coletivo? Como olhar com uma visão para o coletivo? E como podemos buscar em nossos trabalhos a potencialidade da singularidade de cada um nesta relação coletiva? Estas são questões que buscamos problematizar numa abordagem de extensão, que busca estimular a sabedoria numa ótica comunitária, que visa promover a autonomia e a mobilização comunitária dentro de uma perspectiva popular e biocêntrica.

A extensão biocêntrica utiliza a metodologia da Educação Biocêntrica (CAVALCANTE, 2001), que é uma proposta político-pedagógica baseada nos pressupostos de Educação Popular (FREIRE, 1977) e da Biodança (TORO, 2002), e que busca a integração da identidade através dos potenciais genéticos e ambientais no diálogo entre os saberes, assumindo a corporeidade como ponto de partida para a construção do conhecimento. Toro (2002) define os potenciais genéticos como expressões vivenciais do ser humano: vitalidade (ímpeto de viver, movimento), sexualidade (sentir a carícia e o prazer), criatividade (expressão, criar estilos de viver saudáveis), afetividade (nutrição e contato) e transcendência (harmonia e conexão com a vida). Essa metodologia visa, também, refletir sobre uma proposta de formação humana tendo a Vida como valor supremo, em contraponto a um tipo de educação formal direcionada para a informação e o estabelecimento de condutas; considerar os pressupostos da Educação Centrada na Vida como caminho para o desenvolvimento da formação; despertar nos

\footnotetext{
3 Fizemos a opção pelos Guarani pelo fato desta etnia não usar plural. A Antropologia sugere que o uso do plural ou do singular fica a critério dos pesquisadores.
} 
estudantes sua capacidade crítica em relação ao cuidado; e incentivar a abertura para novos paradigmas, refletindo sobre a ação integrada $e$ interdisciplinar.

Em seguida, apresentaremos duas experiências desenvolvidas em dois projetos de extensão, um em uma universidade pública e o outro em uma universidade comunitária.

\section{Nossas vivências no Ceará e no Rio Grande do Sul}

\section{Núcleo de Psicologia Comunitária}

As histórias do Núcleo de Psicologia Comunitária (NUCOM) da UFC e da Psicologia Comunitária no Ceará nasceram juntas no início dos anos 1980 e possibilitaram a expansão do conhecimento da Psicologia que favoreceu a construção de teorias, metodologias e práticas sociais contextualizadas na realidade nordestina, principalmente porque a Psicologia era ou é considerada uma profissão elitista. Não queremos dizer que o que foi construído somente se aplica à terra cearense, pois o enfoque libertário da Psicologia Comunitária (GÓIS, 1993) pode estar presente em qualquer prática que tem esse objetivo. Apresentaremos, posteriormente, uma experiência no Rio Grande do Sul que trabalha com essa Psicologia Comunitária.

Essa caminhada não foi fácil, pois falare praticar uma psicologia, na formação acadêmica e profissional, que faz uma opção pelos pobres e oprimidos, e propõe a transformação social como um horizonte de uma vida humana, feliz e amorosa, constitui-se um desafio social. Muitas vezes, éramos rotuladas de ativistas, politiqueiras e não acadêmicas, principalmente porque vivíamos e praticávamos a Psicologia Comunitária na extensão universitária. Muitos preconceitos estavam presentes nesse percurso: fazer Psicologia Comunitária, desenvolver essa prática na extensão universitária e viver no Ceará. Mas a determinação e a convicção de um projeto social, que possibilitava a construção de uma sociedade mais justa, nos fortificavam.

Com o passar dos anos, conseguimos a incorporação da disciplina obrigatória de Psicologia Comunitária no currículo do Curso de Graduação em Psicologia da UFC, em 19884, criamos vários projetos de extensão e o Núcleo de Psicologia Comunitária em 1992, e vários livros foram escritos, principalmente pelo Prof. Cezar Wagner de Lima Góis. Participamos de vários encontros e congressos, muitos estudantes tornaram-se mestres e doutores, como também professores universitários e psicólogos comunitários, realizamos pesquisas científicas, e desenvolvemos trabalhos de assessoria para o movimento popular e para o poder público.

Podemos afirmar que, a partir do desenvolvimento das políticas públicas, a área de atuação do(a) psicólogo(a) comunitário(a) ampliou-se bastante e quase todos os nuconianos ${ }^{5}$, quando concluem a graduação, passam a atuar em Psicologia Comunitária, principalmente nas políticas públicas. Esse fato não acontecia na década de 80 e 90, do século passado, quando muitos desenvolviam sua prática profissional nas áreas da Psicologia Clínica, Escolar e Organizacional, pois ser psicólogo(a) comunitário(a) não possibilitava a empregabilidade.

O NUCOM é uma escola de formação profissional e pessoal ${ }^{6}$ que possibilita a vivência acadêmica (ensino, pesquisa e extensão) e a vivência comunitária com trabalhos desen-

\footnotetext{
4 Depois da UFMG, fomos o segundo curso de graduação em Psicologia a ter a disciplina obrigatória de Psicologia Comunitária, na década de 80. Atualmente, vários cursos de graduação têm essa disciplina como obrigatória.

5 Estudantes que participam do NUCOM como extensionistas.

6 Nós, autoras deste trabalho, fomos formadas no NUCOM, antes denominado Projeto de Psicologia Comunitária, no período de 1988 a 1993.
} 
volvidos nas comunidades urbanas e rurais do Ceará. A Psicologia Comunitária é considerada uma área da Psicologia Social da Libertação (GÓIS, 2005) que

estuda a atividade do psiquismo decorrente do modo de vida do lugar/comunidade: estuda o sistema de relações e representações, identidade, consciência, identificação e pertinência dos indivíduos ao lugar/comunidade e aos grupos comunitários. Visa ao desenvolvimento da consciência dos moradores como sujeitos históricos e comunitários, através de um esforço interdisciplinar que perpassa a organização e o desenvolvimento dos grupos e da comunidade (GÓIS, 1994, p. 43).

Conceitualizamos comunidade como um espaço vivo que possibilita a construção de laços afetivos e de contradições:

A comunidade, mais além de sua dimensão física, de lugar, que a identifica geograficamente, possui dimensão sócio-psicológica que implica a existência, nesse espaço físico, de uma rede de interação sócio-psicológica e identidade social de lugar. A partir dessas considerações, compreendemos a comunidade como um lugar de moradia, um "lugar" social, de permanência estável e duradoura, de relação direta (face-a-face) entre seus moradores, de crescimento e de proteção da individualidade frente à natureza e à sociedade. Apresenta, como o município e a sociedade maior, que exercem influência sobre ela, um processo social próprio cheio de contradições, conflitos e interesses comuns, que servem de base à construção $e$ orientação das ações dos seus moradores [...] (GÓIS, 2005, p. 61).

No NUCOM, desenvolvemos atividades de ensino - nos grupos de estudos, eventos e cursos de extensão - nos projetos direcionados às comunidades; e de pesquisa - no Programa de Iniciação Cientifica (PIBIC) e em pesquisas financiadas por editais, como é o caso da pesquisa Práticas inovadoras e desinstitucionalização: analisando um movimento comunitário em saúde mental no nordeste do Brasil, que será desenvolvida na comunidade do Bom Jardim, lugar em que temos um projeto de extensão.

As atividades de extensão exigem uma maior dedicação do grupo do NUCOM, que é formado por graduandos em Psicologia e por professores. Atualmente, temos seis projetos de extensão, sendo eles um curso de extensão, um grupo de estudo, um seminário de palestras, todos relacionados à Psicologia Comunitária; uma formação permanente dos integrantes do núcleo; um projeto de saúde comunitária na comunidade do Bom Jardim e outro de desenvolvimento comunitário na Região do Médio Curu (Sertão do Ceará).

O Projeto de Saúde Comunitária acontece em parceria com o Movimento de Saúde Mental Comunitária do Bom Jardim (MSMCBJ) e com o Centro de Apoio Psicossocial (CAPS). Tem como objetivo facilitar o desenvolvimento comunitário a partir do diálogo entre o poder público, os movimentos sociais e os equipamentos sociais, na construção de uma cogestão das políticas públicas, através de estratégias em saúde comunitária (GOIS, 2008). Desenvolvemos atividades semanais na comunidade com os(as) seus(suas) moradores(as) e com os familiares e usuários do CAPS.

O Projeto de Desenvolvimento Comunitário do Médio Curu tem como objetivos contribuir com o desenvolvimento comunitário a partir do fortalecimento de formas participativas e cooperativas de trabalho, que visam ao desenvolvimento socioeconômico local e humano de seus moradores e a desenvolver conceitos $e$ práticas que contribuam com a construção da práxis da Psicologia Comunitária, bem como com a formação de estudantes e profissionais 
engajados(as) na transformação positiva da realidade. Trabalhamosem parceria coma Agência de Desenvolvimento Local (ADEL), formada por estudantes e profissionais da área de Ciências Agrárias. Otrabalhoé desenvolvido conjuntamente com os produtores de ovinocaprinos, apicultores, lideranças comunitárias, e outros atores das comunidades, através de visitas quinzenais em finais de semana.

Atuamos nesses projetos a partir do referencial teórico e metodológico da Psicologia Comunitária (GOIS, 2005; MONTERO, 2003) e das teorias que a compõem como: Psicologia Histórico-Cultural, de Vigotsky, Leontiev e Luria; Biodança, de Rolando Toro; Educação Libertadora, de Paulo Freire; Psicologia da Libertação, de Martín-Baró; e Teoria Rogeriana, de Carl Rogers.

Queremos enfatizar que a vivência (TORO, 2002) é a base de nossos trabalhos.

Por outro lado, somente o ambiente acadêmico não basta. É a comunidade na sua plena dimensão que possibilita esta práxis libertadora. A Psicologia Comunitária sem a presença viva de uma comunidade não pode existir. A vida nas comunidades e o convívio com os seus moradores deflagram processos nas nossas vidas que não seriam vividos sem a presença viva da dinâmica comunitária (XIMENES; GÓIS, 2004, p.11).

\section{VER-SUS Extensão}

VER-SUS Extensão é um projeto de vivências em educação popular no sistema único de saúde, desenvolvido a partir do movimento estudantil, que visou, dentre outros objetivos, o conhecimento da realidade do Sistema Único de Saúde (SUS) e o entrelaçamento desta com o conhecimento universitário. O projeto constitui-se de uma vivência em que alunos de vários cursos (Psicologia, Enfermagem, Nutrição,
Fisioterapia, Medicina, Direito, Comunicação Social, Farmácia, Biologia, Educação Física, etc.) passam um período morando nas comunidades e continuam trabalhando nas mesmas ao longo de um ano.

Destacamos aqui a experiência na Universidade de Santa Cruz do Sul, cujo projeto, financiado pelo Ministério da Saúde, gerou muitos questionamentos sobre a formação universitária. Ele aconteceu em duas comunidades, uma urbana (Bairro Renascença) e outra rural (Rio Pardinho). Em cada uma destas comunidades havia 14 estudantes participantes, dois estudantes facilitadores, duas professoras (cursos de Psicologia e Enfermagem), duas profissionais de saúde representantes da Secretaria Municipal de Saúde de Santa Cruz do Sul e duas agentes de saúde, que participaram ativamente na construção de uma proposta de intervenção comunitária de autogestão.

A Psicologia Comunitária contribuiu ativamente na reflexão metodológica pautada: na Educação Biocêntrica (CAVALCANTE, 2001), que desenvolve uma perspectiva educacional popular deflagradora de processos vitais dentro de uma escuta sensível e afetiva; e no Método Dialógico de Paulo Freire, que problematiza uma intervenção autoritária e etnocêntrica, no qual os valores dos educadores são centralizados em questões fundamentais nas etapas de inserção, como o conhecimento das categorias atividade, consciência, identidade pessoal e coletiva, poder e valor pessoal, vivência e outros, abrindo-nos um campo reflexivo-vivencial de interação comunicativa com as pessoas na comunidade.

Estas percepções nortearam um trabalho minucioso na formação dos grupos, iniciado já no processo de seleção dos facilitadores e dos participantes, bem como na inserção dos grupos nas comunidades, nos olhares e interações que estes foram realizando nos espaços de convivência. No processo de "seleção" foi problematizado este próprio termo, tendo em vista o caráter participativo e de autogestão 
do projeto. Optamos pelo termo "escolha", que pressupõe uma postura ativa diante dos caminhos, nos quais os erros e acertos fazem parte de uma decisão comum partilhada $e$ renegociada permanentemente. Neste momento, trabalhou-se com profundidade a dimensão dos processos grupais, a qual costuma ser excluída por não ser tolerada e pela dificuldade de nos apropriarmos desta como um processo educativo transformador. Estes processos são representados por pessoas, relações, decisões, lutas de poder, enfim, aspectos que podem transformar-se em desintegração grupal quando não são apropriados. Ao contrário, foi-se percebendo, pelas dinâmicas grupais, a importância do sentido de pertencimento, e de identidade pessoal e coletiva, no trabalho comunitário. São vivências que não se separaram daquelas vividas nas próprias comunidades, onde os alunos se deparam com diferenças entre classes sociais, etnias, valores, relações de poder, diversos níveis de exercício de cidadania, problematizações que potencializam a formação profissional $e$ pessoal.

Destacamos a vivência do compartilhar a individualidade em grupo como um grande instrumento de transformação do individualismo silencioso em individualidade conectada ao grupal, ao pertencimento social, vivência essa que produziu olhares e ações reflexivas, impulsionadores de diálogos e de trocas construtivas entre estudantes, professores e comunidades. Tais diálogos nem sempre foram consensuais, mas são geradores de vida e de conhecimento respeitoso. Para as comunidades, houve avanços em suas organizações comunitárias que possibilitaram a construção de uma creche comunitária e a implantação de uma estratégia de saúde da família, bem como a conquista de uma área de lazer. Observou-se uma construção conjunta de uma consciência política tanto para os estudantes quanto para os moradores das comunidades. Houve o que Góis
(2008) descreve como um processo de libertação que liberta na ação, por isso é transformador e gerador de autonomia.

\section{Considerações finais}

A extensão popular e biocêntrica é fruto desses inúmeros diálogos desenvolvidos ao longo de nossa história, composta de encontros e ações com estudantes, professores, técnicos, gestores, políticos, moradores de zona rural e urbana, pescadores, sertanejos, mulheres, indígenas, recicladores de lixo, lideranças comunitárias, etc. Foram saberes constituídos além das disciplinas de nossa formação - Psicologia Comunitária, Educação Popular, Educação Biocêntrica e Biodança. São saberes transdisciplinares, ameríndios, populares e científicos. $\mathrm{O}$ que nos une é a busca da efetivação de sabedoria, ou seja, de saberes geradores de Vida. E, para isso, trabalhamos esperançosamente gerando encontros potencializadores, conexões que integram muitos esforços que estão dispersos $e$ que, por isso, se fragilizam. O que nos move é a crença na organização popular e da própria Vida.

Acreditamos que as universidades possuem um papel fundamental nestes percursos, pois são lugares onde muitos conhecimentos são gerados, espaços nos quais muitos desejam estar, lugares de trocas de saberes, de condições próprias para um pensar, agir e sentir mais integrado. A extensão nos coloca no limiar, nos convoca à Vida, a criar e deixar-se ser criado. No entanto, precisamos estar mais atentos, menos distraídos, menos tensos, para sermos capazes de construir projetos políticos pedagógicos geradores de sabedoria e que propiciem as conexões capazes de produzir Vida decente, encontros de dignidade. 


\section{REFERÊNCIAS}

BATOMÉ, Silvio. Extensão Universitária: equívoco, exigências, prioridades e perspectivas para a universidade. In. FARIA, Dóris Santos de (Org.). Construção Conceitual da Extensão Universitária na América Latina. Brasília: Universidade de Brasília, 2001. p.159-175.

BERGAMASCHI, M. A. NHEMBO 'E! Enquanto o encanto permanece! Processos e práticas de escolarização nas aldeias Guaranis. Tese (Doutorado) - Programa de PósGraduação em Educação, UFRGS, Porto Alegre, 2005.

BRANCO, Alba Lucia Castelo; GUIMARÃES, Regina Guedes Moreira. Problematizando a sistematização dos modelos de extensão e de seus referenciais teóricos. In: THIOLLENT, Michel et al. Extensão Universitária: conceitos, métodos e práticas. Rio de Janeiro: Universidade Federal do Rio de Janeiro, 2003. p. 29-40.

CAVALCANTE, Ruth et al. Educação Biocêntrica - um movimento de construção dialógica. Fortaleza: edições $\mathrm{CDH}, 2001.211 \mathrm{p}$.

FALCÃO, Emmanuel. Vivência em comunidade outra forma de ensino. João Pessoa: UFPB/Editora Universitária, 2006. 154p.

FARIA, Dóris Santos de (Org.). Construção conceitual da Extensão Universitária na América Latina. Brasília: Universidade de Brasília, 2001. 185p.

FRANTZ, Walter; SILVA, Enio Waldir. As funções sociais da universidade - o papel da extensão e a questão das comunitárias. Ijuí: Editora UNIJUÍ, 2002. 248p.

FREIRE, P. Extensão ou comunicação? Rio de Janeiro: Paz e Terra, 1977. 93p.

Pedagogia do oprimido. 18. ed. Rio de Janeiro: Paz e terra, 1987.107p.

GOIS, Cezar Wagner de Lima. Noções de Psicologia Comunitária. Fortaleza: Edições UFC,1993. 146p.

. Psicologia comunitária: atividade e consciência. Fortaleza: Publicações Instituto Paulo Freire, 2005. 237p.

Saúde comunitária. Pensar e fazer. São Paulo:

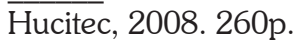

JENIZE, Edineide. A crise da universidade e o compromisso social da extensão universitária. João Pessoa: UFPB/Editora Universitária, 2006. 331p.

MENEZES, A. L. T. A Alegria do corpo-espírito saudável: ritos de aprendizagem Guarani. Tese (Doutorado) - Programa de Pós-Gradução em Educação, UFRGS, Porto Alegre, 2006.

MONTERO, Maritza. Teoria e Práctica de la Psicologia Comunitária. La tensión entre comunidad y sociedad. Buenos Aires: Editorial Paidós, 2003. 201p.
MELO NETO, José Francisco de. Extensão Popular. João Pessoa: UFPB/Editora Universitária, 2006. 97p.

NOGUEIRA, Maria das Dores Pimentel. Políticas de extensão universitária brasileira. Belo Horizonte: Editora UFMG, 2005. 135p.

ROCHA, Roberto Mauro Gurgel. Extensão universitária: momento de aplicação do conhecimento e de intercâmbio de saberes na relação universidade sociedade? In: THIOLLENT, Michel et al. Extensão Universitária: conceitos, métodos e práticas. Rio de Janeiro: Universidade Federal do Rio de Janeiro, 2003. p. 17-28.

SOUSA, Ana Luisa Lima. Concepção de extensão universitária: ainda precisamos falar sobre isso? In: FARIA, Dóris Santos de (Org.). Construção conceitual da Extensão Universitária na América Latina. Brasília: Universidade de Brasília, 2001. p. 107-126.

TAVARES, Maria das Graças Medeiros. Os múltiplos conceitos de extensão. In: FARIA, Dóris Santos de (Org.). Construção conceitual da Extensão Universitária na América Latina. Brasília: Universidade de Brasília, 2001. p. $73-84$.

THIOLLENT, Michel. Metodologia participativa e extensão universitária. In: THIOLLENT, Michel et al. Extensão Universitária: conceitos, métodos e práticas. Rio de Janeiro: Universidade Federal do Rio de Janeiro, 2003. p. 57-67.

TORO, R. A. Biodanza. 2. ed. São Paulo: Editora Olavobrás, 2002. 154p.

UNGER, N. M. Da foz à nascente: o recado do rio. São Paulo: Cortez; Campinas: Editora da Unicamp, 2001. 201p.

XIMENES, V. M.; GOIS, Cezar Wagner de Lima. Núcleo de Psicologia Comunitária - práxis libertadora. In: CONGRESSO BRASILEIRO DE EXTENSÃO UNIVERSITÁRIA, 2., 2004, Belo Horizonte. II Congresso Brasileiro de Extensão Universitária, 2004. v. 1. p. 1-12.

; NEPOMUCENO, Bárbara B; MOREIRA, Ana E. M. M. Cooperação Universitária: uma prática comunitária/ libertadora a partir da Psicologia Comunitária. In: CORDEIRO, Andréa et al. (Orgs.). Psicologia (em) transformação social: práticas e diálogos. Coleção Extensão Universitária/ UFC. Fortaleza: Editora Aquarela, 2007. p. 16- 38.

. Cooperação universitária: um caminho dialógico, libertador e crítico construído no Núcleo de Psicologia Comunitária. In: XIMENES, Verônica et al. (Orgs.). Psicologia comunitária e educação popular: vivências de extensão/universitária no Ceará. Fortaleza: LC Gráfica e Editora, 2008. p. 63-88.

Texto recebido em 16 de fevereiro de 2009. Texto aprovado em 25 de março de 2009. 